\title{
MENGELABORASI HUKUM POSITIF TERTULIS INDONESIA MENGATUR STARTUP
}

\author{
Stephanie PD*1, Natasha OA ${ }^{2}$, Enjelina $S^{3}$, Ahmad Redi $^{4}$ \\ ${ }^{1}$ Jurusan Hukum, Universitas Tarumanagara Jakarta \\ Email: stephanieuntar@gmail.com \\ ${ }^{2}$ Jurusan Hukum, Universitas Tarumanagara Jakarta \\ Email:natashaolivia979@yahoo.com \\ ${ }^{3}$ Jurusan Hukum, Universitas Tarumanagara Jakarta \\ Email: enjellsummerlee@gmail.com \\ ${ }^{4} J u r u s a n$ Hukum, Universitas Tarumanagara Jakarta \\ Email:ahmadr@fh.untar.ac.id
}

\begin{abstract}
The term startup emerged at the end of the 90s between 1998 and 2000. Many new business entities in the field of information technology have emerged using websites as a means of supporting their business. A business entity built to penetrate the market with rapid development. In 2021 in Indonesia, there will be 1 decacorn startup, namely Gojek and 7 unicorn startups, namely Tokopedia, Grab, Traveloka, OVO, Bukalapak, J\&T Express and Lazada. According to Startup Ranking (www.startupranking.com) data, the number of Indonesian startups ranks 5th in the world at around 2,274. This study aims to understand the Indonesian laws and regulations governing startup businesses and the obstacles faced by startup entrepreneurs in starting and running their business activities. Using normative research methods that focus on secondary data. The nature of this research is descriptive by using a qualitative approach to get the symptoms from being studied. The results of this study explain that startup companies to be able to operate legally must comply with the provisions of Law no. 19/2016 which replaced Law No. 11/2008 concerning "Information and Electronic Transactions". Law no. 7/2014 concerning Trade, Presidential Regulation No.74/2017 concerning "Electronic-Based National Trading System Roadmap". The legal breakthrough made by the government is to stipulate Government Regulation no. 20/2019 regarding trading through the online system. The obstacles faced by startups are not registering their business licenses, not paying taxes, forgetting to register intellectual property rights, ignoring the rights and legality of employees.
\end{abstract}

Keywords: startup, positive law, constraint.

\begin{abstract}
ABSTRAK
Istilah startup muncul di penghujung era 90-an antara 1998 sampai 2000. Banyak bermunculan badan usaha baru bidang teknologi informasi dengan menggunakan website sebagai sarana pendukung bisnisnya. Suatu badan usaha yang dibangun untuk melakukan penetrasi pasar dengan perkembangan dalam waktu yang cepat. Pada 2021 di Indonesia tercatat ada 1 startup decacorn yaitu Gojek dan 7 startup unicorn, yaitu Tokopedia, Grab, Traveloka, OVO, Bukalapak, J\&T Express dan Lazada. Menurut data Startup Ranking (www.startupranking.com) jumlah startup Indonesia terbanyak urutan ke 5 dunia sekitar 2.274. Penelitian ini bertujuan untuk memahami peraturan perundang-undangan Indonesia mengatur usaha startup dan hambatan yang dihadapi pengusaha startup dalam memulai dan menjalankan kegiatan usahanya. Menggunakan metode penelitian normatif yang fokus pada data sekunder. Sifat dari penelitian ini deskriptif dengan menggunakan pendekatan kualitatif untuk mendapatkan gejalagejala dari yang diteliti. Hasil penelitian ini menjelaskan Perusahaan startup untuk bisa beroperasi secara legal harus memenuhi aturan Undang-Undang No. 19/2016 yang mengganti Peraturan UU No.11/2008 perihal "Informasi dan Transaksi Elektronik". Aturan perundang-undangan No.7/2014 membahas "Perdagangan", Peraturan Presiden No.74/2017 perihal "Peta Jalan Sistem Perdagangan Nasional Berbasis Elektronik". Terobosan hukum yang dilakukan pemerintah yaitu menetapkan Peraturan Pemerintah No. 20/2019 perihal perdagangan melalui sistem online. Kendalanya yang dihadapi startup tidak mendaftarkan ijin bisnisnya, tidak membayar pajak, lupa mendaftarkan HAKI, mengabaikan hak juga legalitas karyawan.
\end{abstract}

Kata Kunci: startup, hukum positif, kendala. 


\section{PENDAHULUAN}

\section{Latar Belakang}

Startup atau usaha rintisan merupakan bentuk usaha tumbuh di era pemakaian sistem digital cyber physical system. Startup intinya adalah badan usaha yang dirancang untuk berkembang dalam waktu yang relatif cepat, adanya inovasi produk baru yang merusak pasar yang sudah ada sebelumnya. Pembaharuan produk akibat adanya ICT/Information Communication Technology menjadikan hidup manusia lebih mudah. 5 (lima) faktor penentu tingkat keberhasilan usaha rintisan adalah metode bisnis, ide, waktu, tim, dan pendanaan.

Era 90-an istilah startup lahir sekitar 1998-2000. Saat itu banyak perusahaan baru di information technology yang lahir dengan cara menggunakan website. Akibatnya banyak tercipta badan usaha baru dengan menggunakan internet sebagai lahan penghasilan. Jadi istilah startup diidentikkan dengan bisnis yang berkaitan dengan digital dan information technology (Markey, 2019).

Usaha rintisan ialah suatu wadah yang dibangun untuk mendapatkan bentuk usaha yang pasti untuk dengan perkembangan dalam waktu singkat (Afdi \& Purwanggono, 2018). Kata digital maksudnya menggabungkan digitalisasi pada barang atau alur produksinya. Perusahaan rintisan yang berkembang di website, misalkan startup pendidikan, startup hukum, startup kesehatan, startup pertanian, startup fintech lending, startup game. Contoh startup di Indonesia Ecommerce (Lazada, Bukalapak, Tokopedia, Zalora, Blibli, JD ID, Shopee), Online Messenger (WhatApp, LINE, Snapchat), Logistic (J\&T Express, Gojek, Grab, Maxim, InDriver), Travel Agency (Traveloka, Agoda, Airbnb, Pegipegi, Tiket.com), Fintech (HaloMoney, Bitcoin, Kredit Gogo, UangTeman, Modalku). (Krisnandi, et.al)

Saat ini di Indonesia bisnis rintisan berkembang pesat. Semakin dikenal publik karena lahir sejumlah startup unicorn (diatas 1 miliar dollar AS (14 triliun rupiah) nilai valuasinya) dan startup decacorn (nilai valuasinya mencapai diatas 10 miliar dollar AS (141 triliun rupiah)). Berdasarkan data “Bain \& Company's Southeast Asia Private Equity Practice”, Pada 2021 di Indonesia tercatat ada 1 (satu) startup decacorn yaitu Gojek (sebelum merger dengan Tokopedia) dan 7 (tujuh) startup unicorn di Indonesia, yaitu Tokopedia (sebelum merger dengan Gojek), Grab, Traveloka, OVO, Bukalapak, J\&T Express dan Lazada. (Aksara, 2021). Menurut data terupdate (12 september 2021), Startup Ranking (www.startupranking.com) Indonesia sebagai negara dengan jumlah startup terbanyak nomer 5 (lima) didunia yaitu sekitar 2.274 startups.

\begin{tabular}{|c|c|c|}
\hline Flag & Country & Startups \\
\hline 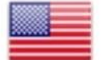 & United States & 68,969 \\
\hline$\infty$ & India & 11,291 \\
\hline $\mathbb{N} \mathbf{D}$ & United Kingdom & 5,894 \\
\hline 4 & Canada & 3,066 \\
\hline$\square$ & Indonesia & 2,274 \\
\hline
\end{tabular}

Gambar 1. Startup Ranking Dunia (12 September 2021) Sumber: www.startupranking.com 
Peta ekonomi dan politik di Indonesia diwarnai oleh eksistensi generasi milenial (generasi muda). Di masa pandemi Covid-19, jumlah investor pasar modal di tanah air terus bertumbuh. Otoritas Jasa keuangan (OJK) mencatat sampai Juli 2021, investor pasar modal sudah mencapai 5,82 juta. Meningkat 93\% secara tahunan dikuasai oleh investor ritel anak muda, berusia dibawah 30 tahun (Sidik,2021). Banyaknya generasi milenial Indonesia yang mengapresiasi dengan mengembangkan dan menciptakan startup di Indonesia. Keseriusan pemerintah Indonesia dalam mendukung pengembangan startup diwujudkan dengan mengeluarkan Aturan Kepala Badan Perekonomian Kreatif Republik Indonesia No.10/2016 perihal pemerintah memberi bantuan permodalan awal Pemerintah bagi usaha rintisan. Tujuan pemerintah adalah 1) meningkatkan dan mengembangkan rintisan usaha bisnis. 2) Mendorong perkembangan rintisan usaha bisnis, organisasi, masyarakat dan lembaga pengajaran yang berhubungan dengan rintisan usaha bisnis untuk membuka lapangan kerja, punya potensi untuk bersaing dan kesejahteraan masyarakat. 3) Menumbuhkan juga meningkatkan daya saing rintisan usaha (startup). Jenis bantuan pemerintah berupa pendanaan. Yang berhak menerima bantuan pemerintah ialah rintisan usaha bisnis yang sudah menjalani proses pembinaan atau sedang pembinaan oleh inkubator, prioritas bagi anggota program BEK-UP Pre-Startup. Inkubator usaha ialah institusi pelaksana prosedur inkubasi bagi rintisan usaha bisnis via bermacam-macam pembimbingan terpadu diantaranya penyediaan tempat usaha, fasilitas tempat usaha, pelatihan, pembinaan dan dengar pendapat, research and development, pendanaan, dan networking.

Pendekatan populer hukum \& kebijaksanaan ajaran Oliver Wendell Homes yaitu sebuah penalaran hukum harus bisa melahirkan tujuan-tujuan sosial. Hukum bekerja mengikuti kejadian-kejadian konkret yang timbul. Pendekatan interdisipliner dengan memanfaatkan disiplin ilmu mendukung bekerjanya hukum; sosiologi, kriminologi, psikologi dan ekonomi. Menyelidiki faktor sosial berpatokan pada pendekatan teresbut dengan menyeimbangkan antara apa yang menjadi harapan hukum dan kenyataan kehidupan sosial masyarakat. Muaranya agar hukum bisa bekerja jauh lebih lanjut. Teori hukum Fitzerald menjelaskan tujuan hukum menyatukan dan menyelaraskan bermacam-macam harapan kehidupan sosial. Memproteksi hak yang satu akan berdampak pada pembatasan hak lain pihak. Kepentingan hukum ialah mendelegasikan hak dan kewajiban manusia, menjadikan hukum mempunyai otoritas tertinggi guna memastikan mana keperluan harus ditata dan dijaga. Perlindungan hukum ialah usaha mengayomi HAM dalam keadaan diganggu pihak lain, proteksi agar segala hak yang telah diberikan hukum dapat dinikmati khalayak (Raharjo, 2000).

Rudiantara dalam acara Startups \#Gopublic di BEI 28 Februari 2018, rabu pukul 15:46 WIB. Menyampaikan bahwa pemerintah membuka kesempatan seluasnya. Mendirikan startup tidak perlu izin. Hanya perlu registrasi dan bisa dilakukan secara online. Pemerintah terus membuat regulasi yang sederhana (Putri, 2018). Menurutnya dalam berinovasi membuat usaha rintisan boleh melanggar peraturan tertentu, tapi usaha tersebut harus memberikan nilai tambah buat kehidupan juga bermanfaat bagi masyarakat. Sebagai grundnorm UUD 45 pantang dilanggar.

Regulasi mendirikan startup:

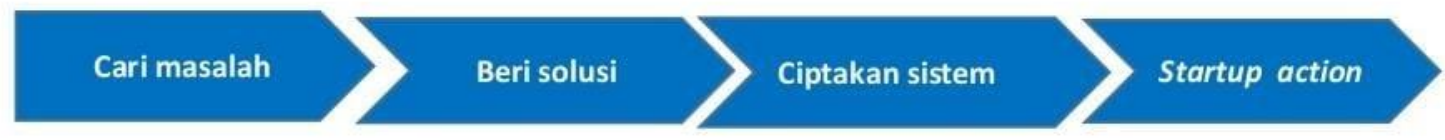

Kemudahan dan fasilitas yang diberikan oleh pemerintah untuk mendukung pertumbuhan startup di Indonesia, memicu tumbuhnya pertumbuhan startup juga mengakibatkan banyak kegagalan 
sejalan dalam pertumbuhannya. Hal ini disebabkan terlalu sedikit pengetahuan pebisnis dasar hukum dalam membangun startup. Sebelum memulai usahanya, pelaku bisnis startup harus mengkaji secara matang hukum peraturan perundang-undangan Indonesia yang mengatur usaha startup, juga mempelajari kendala-kendala yang akan dihadapi pada saat memulai dan menjalankan kegiatan usahanya. Sehingga resiko kegagalan dalam menjalankan usaha startup bisa diminimalisir.

Sesuai uraian yang dijelaskan di latar belakang, maka penulis mengidentifikasikan rumusan permasalahan sebagai berikut:

1. Bagaimanakah peraturan perundang-undangan tertulis Indonesia mengatur usaha startup?

2. Kendala-kendala apa saja yang dihadapi pengusaha startup dalam memulai dan menjalankan kegiatan usahanya?

\section{METODE PENELITIAN}

Penyusunan artikel dengan metode penelitian hukum normatif, fokus pada data sekunder (Soekanto \& Mamudji, (2021)). Yang meliputi bahan hukum primer (perundang-undangan, peraturan pemerintah, peraturan presiden). Bahan hukum sekunder (buku pendukung, jurnal terkait usaha rintisan, artikel). Bahan hukum tersier (kamus bahasa Indonesia). Sifat dari penelitian ini deskriptif dengan menggunakan pendekatan kualitatif untuk mendapatkan pemahaman gejala-gejala dari yang diteliti. Keseluruhan bahan hukum yang ada dipilih, disortir dan dianalisi kemudian diharmonisasikan dengan peraturan perundang-undangan terkait.

\section{HASIL DAN PEMBAHASAN}

\section{a. Peraturan perundang-undangan Indonesia Mengatur Usaha Startup}

Pasal 28 C Ayat (1) UUD'45 sebagai grundnorm (moral dasar), merupakan dasar pondasi filosofis di Indonesia yang mendasari perkembangan teknologi, menyatakan bahwa setiap pribadi berhak memajukan diri dengan memenuhi kebutuhan dasar, punya hak mengenyam pendidikan juga merasakan faedah dari IPT, kesenian \& kebudayaan, guna menaikkan taraf kehidupan juga kesentosaan sosial. Bukti negara mendukung dan menjamin IPTEK. Setiap warga negara punya hak memaksimalkan talenta dari Tuhan, termasuk teknologi informasi.

Aturan perundanga Indonesia menata perspektif hukum TIK, sekarang sentralis bertaut pada aturan UU “Informasi dan Transaksi Elektronik". (Ulya \& Musyarri, 2020).

Proses panjang pembentukan rezim Hukum Siber di Indonesia. Awal mula kajian Hukum Siber telah dilakukan semenjak tahun 1999 sebelum dibuatnya "Peraturan Undang-Undang Informasi dan Transaksi Elektronik". Digagas oleh oleh "Pusat Studi Cyberlaw Fakultas Hukum Universitas Padjajaran bersama dengan Jurusan Teknologi Elektro Institut Teknologi Bandung dan Direktorat Jenderal Pos dan Telekomunikasi". Lahirlah "Naskah Akademik Rancangan Undang-Undang Pemanfaatan Teknologi Informasi”. Ditahun 2000 Lembaga Kajian Hukum Teknologi Informasi Fakultas Hukum Universitas Indonesia dengan Disperin berkontribusi mengatur Cyber-Law yaitu "Naskah Akademik Rancangan Undang-Undang Informasi Elektronik dan Transaksi Elektronik". 25 Maret 2008 dibawah koordinasi Presiden, 2 naskah akademik tadi kemudian disesuaikan dan disinkronkan bersama DPR \& pemerintah 2008. 21 April 2008 Presiden menetapkan sebagai aturan UU No. 11/2008 (UU 11/2008) mengenai ITE Inilah lahirnya rezim Cyber Law Indonesia. UU 11/2008 Pasal 9 berisi perlindungan konsumen e-commerce yaitu pebisnis online yang menawarkan produk melalui internet harus memberikan keterangan yang komplit dan tepat mengenai persyaratan kontrak, pebisnis dan barang/jasa yang ditawarkan. Berjalannya waktu direvisi dengan aturan UU No. 19/2016 mengenai gubahan UU 11/2008 perihal keterangan perdagangan melalui website.

Binis melalui sistem internet sekarang diatur melalui PP 80/2019 perihal transaksi mengenai sistem perdagangan melalui elektronik (PP 80/2019). Lingkup pengaturan hukum PP No. 
80/2019 meliputi seluruh perdagangan bermacam-macam sistem \& jenis jaringan komunikasi elektronik melalui pembelian langsung maupun internet. Termasuk hubungan hukum antar pebisnis/business to business atau pebisnis dan pemakai/business to customer. Melalui regulasi ini, online market yang bisnisnya berjalan secara berkala wajib memiliki izin usaha guna memberikan perlindungan secara hukum kepada pemakainya. Namun permasalahannya tidak diikuti sanksi pidana atau administratif. PP No. 80/2019 merupakan peraturan pelaksanaan Pasal 66 Undang-Undang No. 7/2014 mengenai "Perdagangan". Aturan 'Peraturan Pemerintah No. 74/2017' perihal "Peta Jalan Sistem Perdagangan Nasional Berbasis Elektronik". Juga dijadikan acuan bagi startup.

Pendirian startup harus mengurus beberapa dokumen perizinan, yaitu: "Surat Izin Usaha Perdagangan (SIUP)".Dokumen yang harus dimiliki perdagangan. Permohonannya didasarkan pada 'PP No. 24/2018' membahas "Pelayanan Berizin Berusaha Terintegrasi Secara Elektronik atau Online Single Submission (OSS)". Perundangan baru mengupas SIUP tertera pada Permendag No.7/2017: "Perubahan Ketiga Atas Permendag No. 36/2007 tentang SIUP”. Surat izin ini berlaku sepanjang perusahaan menjalankan usahanya; Izin Usaha Industri (IUI), wajib dimiliki startup yang menjalankan bisnisnya melalui digitalisasi; 'Tanda Daftar Perusahaan/TDP' akta validasi wajib dimilik usaha rintisan. Akta ini merupakan langkah terakhir saat proses pendirian badan usaha rintisan. Pengajuannya dilengkapi, Akta Pendirian Perusahaan, NPWP, SIUP, IUI. Dasar hukum TDP Permendag No. 8/2017 perubahan kedua pada Permendag No. 37/2007 perihal "Penyelenggaraan Pendaftaran Perusahaan"; Khusus startup dibidang keuangan atau Financial Technology (fintech) harus mendapat izin OJK \& BI. (Syahroni, 2021); Persyaratan perizinan penyelenggaraan jaringan elektronik, mengikuti aturan Pasal 73 Permenkominfo No. 7/2018 membahas "Pelayanan Perizinan Berusaha Terintegrasi Secara Elektronik Bidang Komunikasi Dan Informatika"; Pegesahan "Hak Kekayaan Intelektual/HKI" merupakan suatu keharusan untuk memberikan perlindungan merek dagang, produk, layanan digital. Hak-hak eksklusif HKI ialah intangible asset bernilai ekonomi tinggi juga meningkat sesuai valuasi badan usaha. Aturan hukum UU No. 28/2014: "Hak Cipta", UU No.29/2000:"Perlindungan Varietas Tanaman", UU No.30/2000:"Rahasia Dagang", UU No. 31/2000:"Desain Industri", UU No.32/2000;"Desain Tata Letak Sirkuit Terpadu", UU No.14/2001:"Paten", UU No.15/2001:"Merek".

Agar bisa berkembang dan maju, startup harus memahami jenis badan usaha dan legalitasnya. Badan Usaha yang sering menjadi pilihan startup adalah 'Perseroan Terbatas/PT badan usaha berbadan hukum'. Dasar hukumnya UU No.40/2007:"Perseroan Terbatas". Diperbarui aturan UU No. 11/2020 dinamai UU Cipta Kerja (UU CK) Pasal 109 tentang Perseroan Terbatas. Dasar hukum Firma (Fa) sama dengan "Commanditaire Vennootschap (CV)". Pasal 15-35 KUHD. CV secara khusus diatur pada Pasal 19, 20,21. CV bentuk khusus Firma (Fa), maka ketentuan pendiriannya. Firma dan CV tidak berbadan hukum. Sering dipilih startup adalah PT dan CV. Kelebihan dan kekurangan PT; kelebihan : jika terjadi kerugian tidak menyeret harta pribadi, tidak ada batas waktu, nama badan usaha dilindungi UU, dipercaya dan profesional, berbentuk saham kepemilikan mudah dialihkan, kekurangan: patuh kepada RUPS, kewajiban pajak, laporan keuangan berkala. Kelebihan dan kekurangan CV; kelebihan: Persyaratan dan prosedur pendiriannya lebih mudah, biaya pendirian lebih murah, modal tidak ditentukan, tidak ada ketentuan organ badan usaha, lebih besar kesempatan peminjaman kredit dari pihak ketiga, manajemen dapat didiversifikasi, lebih mudah berkembang, pengajuan bisa melalui online di laman Kemenkumham https://ahu.go.id ). Kekurangan CV (tanggungjawab tidak terbatas pada sekutu komplementer bisa melibatkan harta pribadi, modal yang disetor sulit ditarik kembali, kelangsungan hidup perusahaan tidak terjamin, sekutu komplementer bisa melakukan pengambilan keputusan tanpa intervensi dari sekutu komanditer sebagai penyetor modal, sehingga kewenangannya tidak ada yang mengawasi). 
Perihal pajak, tidak ada pajak khusus untuk startup electronic commerce. Hanya pemberitahuan edaran Dirjen Pajak No. SE/62/PJ/2013 menerangkan pada transaksi electronic commerce tidak ada aturan baru perpajakan. Pelaksanaannya mengikuti aturan perpajakan konvensional pebisnis dan pemakai dikenai pajak sesuai dengan aturan perpajakan yang dipakai sekarang. Mengelaborasi aturan perundangan Indonesia yang mengatur startup, terlihat dengan jelas bahwa belum ada regulasi khusus untuk startup. Pendekatan hukum yang dilakukan Startup, dengan mengadopsi aturan UU Indonesia yang berlaku disesuaikan dengan badan usaha pilihan $\&$ aktifitas startup menjalankan usahanya.

\section{b. Kendala-kendala Yang Dihadapi Pengusaha Startup Dalam Memulai Dan Menjalankan Kegiatan Usahanya.}

kesempatan pengembangan startup Indonesia baik didalam maupun diluar negeri tidak sebanding dengan kesuksesan yang diraih. Penilaian gagal sebuah usaha rintisan saat tidak berkembang dan rugi. Shikar Ghosh peneliti senior Harvard School mengemukakan tingkat ketidakberhasilan startup sebesar 95\% (Gage, 2012). Forbes.com penulis Patel menyatakan "Dari 10 startup digital yang dibuat, maka 9 diantaranya akan mengalami kegagalan. Singkatnya 90\% kemungkinan sebuah startup untuk gagal. Kegagalan pertama adalah berada pada titik 120 hari (seratus dua puluh hari pertama)" (Patel, 2015).

Startup yang mampu menghadapi segala rintangan dari saat memulai sampai menjalankan usahanya akan menjadi startup dengan mempunyai nilai valuasi yang sesuai dengan gelar startup yang ditetapkan secara global dunia, yaitu startup unicorn, gelar unicorn adalah usaha yang mempunyai nilai valuasinya setahun mencapai satu miliar dollar Amerika atau sekitar 14 triliun rupiah. Startup decacorn, gelar khusus dimiliki startup yang menembus angka valuasi 10 miliar dollar Amerika atau sekitar 142 triliun rupiah per tahun (kurs saat artikel ditulis), sementara hectocorn diberikan pada startup dengan nilai valuasi mencapai 100 miliar dollar Amerika atau sekitar 1.420 triliun rupiah. Gelar hectocorn hanya bisa didapat jika perusahaan belum Initial Public Offering (IPO).

Masalah hukum yang paling banyak dihadapi oleh startup sebagai berikut: tidak mendaftarkan izin usahanya, sebelum melakukan proses perizinan harus didahului dengan pemilihan jenis badan usaha yang sesuai, yaitu Peseroan Terbatas (PT), Firma (Fa), Commanditaire Vennootschap (CV). Pemilihan ini penting berhubungan dengan proses perizinan dan pertanggungjawaan secara hukum pendiri; Tidak memperhatikan perpajakan. NPWP wajib dibuat oleh startup jika berharap bisnisnya bisa bertahan dan terus berkembang. NPWP diperlukan saat mengurus "SIUP dan TDP"; Tidak mendaftarkan HAKI produk atau jasa yg ditawarkan sehingga dapat digunakan tanpa izin oleh orang lain, pemilik startup kehilangan haknya keuntungannya ketika digunakan orang lain. Bahkan mungkin kehilangan hak untuk menggunakan produk yang diciptakannya; Hak dan legalitas karyawan tidak dipenuhi. Hal ini berkaitan dengan aturan perusahaannya dan kesepakatan kerja tertulis mengatur hak dan kewajiban bagi pemilik dan pegawai. Jadi karyawan mendapat keterangan terbuka tentang "penghasilan berserta pajak terkait, asuransi kesehatan, BPJS ketenagakerjaan, bonus dl"; Tidak adanya perjanjian pemegang saham (Shareholders Agreement). Startup sebagai usaha rintisan sering dibangun atas dasar kepercayaan, sehingga sering mengabaikan masalah hukum. Guna mengantur kewenangan para pemegang saham dan perihal penjualan saham.

Penerapan hukum oleh startup bertujuan mengintegrasikan dan mengkoordinasikan kepentingan dalam masyarakat yang menggunakan sistem bisnisnya. Perlindungan terhadap pelaku bisnis rintisan akan membatasi hak dari pemakainnya demikian juga sebaliknya. Kepentingan hukum dalam usaha rintisan mengurusi hak dan kepentingan manusia yang terlibat dalam transaksi online, sehingga hukum memiliki otoritas tertinggi mengatur dan melindungi kepentingan yang ditentukan. Bertujuan untuk memberikan perlindungan hukum bagi para pelaku bisnis online. 
Dengan memahami kendala dalam legalitas startup, maka dalam perkembangannya startup akan mampu memperkecil angka kegagalan, sehingga startup bisa berkembang. Adapula hambatan yang sering dihadapi startup bertumbuh yaitu perubahan teknologi yang cepat, manajemen perusahaan, kegigihan sesuai tujuan perusahaan jadi kiat usaha rintisan bersaing dengan yang telah mencapai gelar unicorn, decacorn atau hectocorn. Bisnis rintisan juga perlu mengedepankan kesejahteraan SDM, menepati janji, bisa dipercaya, menjalankan bisnis dengan bertanggungjawab dan disiplin.

\section{KESIMPULAN DAN SARAN Kesimpulan}

Dari sisi hukum perusahaan, startup dengan karakteristiknya dibebaskan untuk memilih jenis badan usaha. Jenis yang paling banyak dipilih Perseroan Terbatas atau Persekutuan Komanditer, sehubungan dengan sifat dari kepemilikan harta perusahaan, tidak memberikan perlindungan kepada investor. Dalam hukum investasi, Badan Koordinasi Penanaman Modal sulit mengawasi dana pemodalan usaha rintisan dikarenakan belum ditetapkan aturan perundangan startup yang merupakan penggabungan hukum dan teknologi.

Perusahaan startup untuk bisa beroperasi secara legal, harus menjalankan aturan dasar hukum yang menjadi landasannya, diantaranya aturan UU 19/2016 perihal pengantian aturan UU 11/2008 mengupas tentang transaksi elektronik beserta informasinya, peraturan UU 7/2014 membahas perdagangan. PP 74/2017 berisi pemetaan sistem dagagng nasional berdasarkan sistem online.

Peluang perkembangan startup dalam \& luar negeri tidak linier dibanding taraf kesuksesan startup. Startup yang mampu menghadapi segala rintangan dari saat memulai sampai menjalankan usahanya akan menjadi startup dengan mempunyai nilai valuasi yang sesuai dengan gelar startup yang ditetapkan secara global dunia, yaitu startup Unicorn, Dekacorn dan Hectocorn. Permasalahan hukum yang sering dihadapi pengusaha startup tidak mengantongi izin usaha, pengabaian perpajakan, tidak mendaftarkan kekayaan intektualnya, karyawan diabaikan legalitas dan haknya dan tidak adanya perjanjian tertulis antara pemegang saham, Dengan memahami kendala dalam legalitas startup, maka dalam perkembangannya startup akan mampu memperkecil angka kegagalan, sehingga startup bisa berkembang berjaya di negeri sendiri.

\section{Saran}

Dalam memilih jenis badan usaha, penulis menyarankan pelaku startup memilih Perseroan Terbatas (PT). Karena kejelasan status badan hukumnya, juga ada pendelegasian tugas juga wewenang yang jelas diantara organ PT; direksi/pengelola perusahaan, komisaris/ pengawas dan penasihat, RUPS/punya kewenangan eksklusif yang tidak dimiliki organ PT yang lain). Jika startup kedepan mencapai level unicorn, decacorn atau hectocorn maka pelaku startup tidak perlu merubah lagi jenis badan usahanya sehingga tidak perlu mengeluarkan dana double.

Terobosan hukum yang dilakukan pemerintah dengan menetapkan PP 20/2019 perihal perdagangan sisitem online. Menetapkan aturan marketplace yang melakukan transaksi berkelanjutan harus mendaftarkan usahanya guna melindungi secara hukum namun kewajiban $\mathrm{t}$ tidak didukung sanksi pidana atau adminitratif. Dalam kenyataannya sering konsumen menjadi pihak yang dirugikan tanpa bisa menuntut sesuai dengan jalur hukum yang seyogyanya. Misalkan adanya lapak bodong yang hampir ada disetiap market place, jumlah atau kualitas barang tidak sesuai dengan transaksi nilai yang dibayar, pengiriman yang tidak tepat waktu dll.

Pemerintah selayaknya menerbitkan payung hukum khusus startup. Sehingga daya dorong dan perlindungan bisa maksimal terhadap pertumbuhan dan kelangsungan startup di Indonesia. Perlindungan menyeluruh harus bisa diwujudkan dengan adanya payung hukum tersebut, baik 
dari segi pemilik startup, pemakai maupun penanam modal dalam dan luar negeri. Sehingga jalur hukum bisa ditempuh jika ada permasalahan yang ditemui. Selain mengeluarkan payung hukum perundang-undangan, pendampingan untuk memberikan pemahaman legalitas hukum bagi pelaku startup juga harus dilakukan agar efektifitas dari perundang-undangan bisa terealisasi.

\section{Ucapan Terima Kasih}

Terima kasih kepada Bapak Yuwono Prianto, S.H., M.H. sebagai dosen pembimbing

\section{REFERENSI}

Afdi,Z \& Purwanggono,B. (2018). "Perancangan strategi berbasis metodologi lean sartup untuk mendorong pertumbuhan perusahaan rintisan berbasis teknologi di Indonesia" $\begin{array}{lllll}\text { Industrial Engineering } & \text { Online } & \text { Jurnal, } & \text { Vol.6, } & \text { No.4 }\end{array}$ https://ejournal3.undip.ac.id/index.php/ieoj/article/view/20398 diakses pada 6 Juni 2021.

Aksara, D. '(2021)'. “Ada Pendatang Baru! Ini Daftar Terbaru Unicorn di Indonesia 2021” 27 april 'https://bigalpha.id/news/ada-pendatang-baru-ini-daftar-terbaru-unicorn-di-indonesia$\underline{2021^{\prime}}$

Anonim. (2021). Startup Ranking. "Senpex" website www.startupranking.com diakses pada 6 Juni 202 diakses pada 6 Juni 2021.

Gage, D. (2012). "The Venture Capital Secret: 3 Out of 4 Start-Ups Fail". 'Wall Street Journal.

'https://www.wsj.com/articles/SB1000087239639044372020457800498047642919'

Indonesia, Kemenperin HAKI. (2007). "Kebijakan Pemerintah dalam Perlindungan Hak Kekayaan Intelektual dan Liberalisasi Perdagangan Profesi di Bidang Hukum. Direktorat Jenderal Industri Kecil Menengah Departemen Perindustrian".

Indonesia, Peraturan KBEK. (2016). Peraturan kepala Badan Ekonomi Kreatif Republik Indonesia Nomor 10 tahun 2016 tentang tentang Pemberian Bantuan Pemerintah Untuk Pendanaan Awal Rintisan Usaha Bisnis (Start Up). https://jdihn.go.id/files/595/PERKA BEKRAF NO. 10 TAHUN 2016 TENTANG PEMBERIAN BANTUAN PEMERINTAH UNTUK PENDANAAN -compressed.pdf diakses pada 6 Juni 2021.

Indonesia, PP. (2019). Peraturan Pemerintah Nomor 80 Tahun 2019 tentang Perdagangan Melalui Sistem Elektronik. LN.2019/No.222, TLN No.6420.

Indonesia, PERPRES. '(2017)'. Peraturan Presiden Nomor 74 Tahun 2019 tentang Peta Jalan Sistem Perdagangan Nasional Berbasis Elektronik (Road Map e-Commerce) Tahun 2017-2019. LN. 2017/No.176.

Indonesia, UUD. (1945). Undang-Undang Dasar Republik Indonesia Tahun 1945 Pasal 28. Indonesia, UU. (2014). Undang-Undang Nomor 7 Tahun 2014 tentang Perdagangan. LN.2014/No.45, TLN No.5512.

Indonesia, UU. (2016). Undang-Undang Republik Indonesia Nomor 19 Tahun 2016 tentang Perubahan Atas Undang-Undang Nomor 11 Tahun 2008 tentang Informasi dan Transaksi Elektronik. LN. 2016/No.251, TLN No.5952.

Indonesia, UU. (2001). Undang-Undang No. 14 Tahun 2001 tentang Paten. LN.2001/No.109, TLN No.4130.

Indonesia, UU. (2007). Undang-Undang Nomor 28 Tahun 2007 tentang Perubahan Ketiga Atas Undang-Undang Nomor 6 Tahun 1983 tentang Ketentuan Umum dan Tata Cara Perpajakan. LN.2007/No. 85.

Indonesia, UU. (2007). Undang-Undang Nomor 40 Tahun 2007 tentang Perseroan Terbatas. LN.2007/No. 85. 


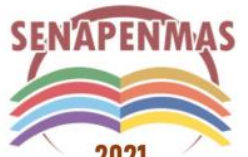

2021
Seminar Nasional Hasil Penelitian dan Pengabdian Kepada Masyarakat 2021

Pengembangan Ekonomi Bangsa Melalui Inovasi Digital Hasil Penelitian dan Pengabdian Kepada Masyarakat Jakarta, 21 Oktober 2021

Indonesia, UU. (2020). Undang-Undang Nomor 11 Tahun 2020 tentang Cipta Kerja. LN.2020/No.245, TLN No.6573.

Isharyanto. (2016). “Teori hukum”. WR Penerbit, Jakarta.

Krisnandi, I. Et.al. "Regulasi Mendirikan Startup di Indonesia". https://www.academia.edu/36997682/Regulasi Mendirikan Startup di Indonesia' diakses pada 6 Juni 2021.

Markey, (2019). "Startup Company: Pengertian dan Perkembangannya.” Markey.id, 18 oktober. https://markey.id/blog/bisnis/entrepreneurship/startup-company

Patel, N. (2015). "90\% of Startup Fail: Here's What You Need To Know About The 10\%." https://www.forbes.com/sites/neilpatel/2015/01/16/90-of-startup-will-fail-heres-whatyou-need-to-know-about-the-10/ diakses pada 6 Juni 2021.

Putri, ND. (2018). "Rudian berupaya permudah IPO strart-up." Kontan.co.id, 28 Februari https://investasi.kontan.co.id/news/rudiantara-berupaya-permudah-ipo-start-up

Rahardjo, S. (2021). "Ilmu Hukum” Citra Aditya Bakti, Bandung.

Soerjono, S \& Mamudji, S (2021). "Penelitian Hukum Normatif Suatu Tinjauan Singkat. RajaGrafindo Persada, Depok.

Suharso \& Retnoningsih, A. (2014). Kamus Besar Bahasa Indonesia. Widya Karya, Semarang

Syahroni, I. (2021). “Aspek-Aspek Hukum dalam Pendirian Start-Up” Heylawedu.id, 11 januari https://heylawedu.id/blog/aspek-aspek-hukum-dalam-pendirian-start-up

Sidik, S. (2021). "Didominasi Milenial, Investor Pasar Modal Capai 5,8 juta." CNBC Indonesia, 10 Agustus $\quad$ https://www.cnbcindonesia.com/market/20210810112137-17267461/didominasi-milenial-investor-pasar-modal-capai-58-juta diakses pada 6 Juni 2021.

Ulya, NU. \& Musyarri, FA. (2020). “Omnibus Law Tentang Pengaturan Teknologi Informasi Dan Komunikasi Guna Rekonstruksi Konvergensi Hukum Teknologi” Jurnal RechtsVinding, Media Pembinaan Hukum Nasional, Vol.9, No.1, April 2020, 53-70. 
(halaman kosong) 